\title{
Os sentidos da escola e da Educação Física para estudantes e docentes de uma rede pública municipal
}

Lisandra Oliveira e Silva*

Vicente Molina Neto**

\begin{abstract}
Resumo: Considerando que recentes mudanças históricosociais têm gerado efeitos na vida da escola, esta pesquisa objetivou compreender os sentidos da escola e da Educação Física a partir dos significados conferidos por docentes e estudantes de uma Rede Pública Municipal. Servindonos de observações participantes, diário de campo, entrevistas e análise de documentos, como opções teóricometodológicas, construímos cinco categorias interpretativas, foco de discussão deste artigo: Escola e as relações com o conhecimento; Escola e Educação Física; Escola e os desafios vividos pelos colaboradores no seu cotidiano na atualidade, Escola, mudanças e projetos; Pensar o sentido da escola é pensar o sentido da vida.
\end{abstract}

Palavras-chave: Escola. Educação Física. Docentes. Estudantes.

\section{Considerações introdutórias}

Considerando que recentes mudanças histórico-sociais têm gerado efeitos na vida da escola e na comunidade escolar, realizamos esta pesquisa para compreendermos os sentidos construídos sobre a escola e a Educação Física a partir das narrativas de dois grupos: o professorado, representado por sete docentes de Educação Física; e os estudantes, representados por 12 jovens matriculados(as) no Ensino Fundamental de duas escolas da Rede Municipal de Ensino de Porto Alegre (RMEPA) e que frequentam as aulas de

\footnotetext{
*Centro de Ciências da Saúde, Departamento de Educação Física, Universidade Federal do Rio Grande do Norte, Natal, RN, Brasil. E-mail: lisgba@yahoo.com.br.

**Escola de Educação Física, Universidade Federal do Rio Grande do Sul, Porto Alegre, RS, Brasil. E-mail: vicente.neto@ufrgs.br
} 


\section{Artigos Originais}

Lisandra O. e Silva, Vicente M. Neto

Educação Física nas escolas. Em nosso entendimento, a escolha das escolas e colaboradores(as) para esta pesquisa consideraram o critério da representatividade tipológica, ao representar escolas antigas e novas na RMEPA; escolas com número pequeno e grande de estudantes; docentes iniciantes e em fase de encerramento da carreira; docentes com carga horária semanal de trabalho de 20 a 40 horas; estudantes que estão matriculados(as) nas escolas desde o ciclo $\mathrm{C}$ e estudantes que realizaram todo o Ensino Fundamental nas escolas pesquisadas (ciclos $\mathrm{A}, \mathrm{B}$ e $\mathrm{C})^{1}$; estudantes que vivenciam os projetos e programas que fazem parte do cotidiano da escola, dentre outros.

Compreendendo a escola como uma instituição educativa em permanente reconstrução pelos sujeitos que nela interagem cotidianamente, apresentamos o entendimento de Pérez Gómez (1998), que a percebe como uma "encruzilhada de culturas", porque fazem parte desse contexto diversos grupos que se organizam de modo diferenciado: docentes, estudantes, funcionários(as), equipe diretiva, núcleo familiar de estudantes, comunidade onde a escola está localizada, Secretaria de Educação, dentre outros. O autor chama a atenção para os conceitos de "cultura experiencial" - o processo de construção de sentidos e de significados realizados por estudantes em seus diversos contextos de vida, ou seja, para além da escola, em suas relações familiares, comunitárias, afetivas, dentre outras -; e "cultura social", constituída pelos valores influentes de determinado contexto histórico-social, por exemplo, a cultura da própria escola.

Arroyo (2000) compreende a prática pedagógica como um "convívio de gerações". Dessa forma, é possível pensar que constituem a escola sujeitos de diferentes tempos geracionais, visões de mundo, desejos, interesses e valores, que passarão juntos

\footnotetext{
'Desde o ano 2000, todas as escolas da RMEPA passaram a ser cicladas. Essa organização do sistema de ensino divide o Ensino Fundamental em três ciclos e cada ciclo se desenvolve em três anos. No ciclo A, estão organizados estudantes de 6 a 9 anos de idade; no ciclo B, estudantes de 9 a 12 anos; no ciclo C, de 12 a 15.
}

Movimento, Porto Alegre, v. 20, n. 3, p. 1139-1158, jul./set. de 2014. 
parte de seu tempo, em situações de aula, dia após dia, durante anos, em um contexto social específico que é a escola.

Sobre o que se faz e o que se intenciona na escola, Moreira e Silva (1995) destacam a importância do currículo escolar como forma de seleção, organização e produção de relações interculturais (docentes, estudantes, grupos de referência e acadêmicos). Os autores tratam esse tema como o centro da ação educacional e ressaltam a perspectiva crítica do currículo, compreendendo-o muito além de aspectos técnicos, procedimentais e metodológicos, o que significa: (1) enfatizar sua intenção sociopolítica, ao conceder prioridade às relações de poder e de controle presentes no processo de organização do conhecimento escolar; e, (2) questionar o como interligado ao porquê no que se refere aos conhecimentos que fazem parte do currículo. Assim, o currículo é entendido como uma forma concreta de constituição de identidades individuais e sociais atravessadas por relações de poder, e, ainda, como um artefato histórico, social e contingente, sendo, portanto, passível de mudanças.

Ao analisarmos essas reflexões percebemos que, para construir conhecimentos sobre os sentidos da escola na atualidade, necessitamos compreender as culturas que constituem o contexto escolar. Para tanto, procuramos compreender o problema de conhecimento com base na escuta, ouvindo as pessoas envolvidas no processo educativo escolar; mesmo reconhecendo que as perspectivas são constituídas em contextos diferentes: a perspectiva da cultura docente e da cultura estudantil. Dessa forma, consideramos a observação de Sancho Gil (1999, p. 35) ao ressaltar as "[...] características e peculiaridades da escola como instituição, com uma história, uma organização e uma confluência de biografias". A partir disso, o problema de conhecimento orientador desta pesquisa foi sintetizado na seguinte questão: Na atualidade, quais sentidos são conferidos à escola e à Educação Física pelo professorado dessa área de conhecimento e pelos estudantes do Ensino Fundamental da Rede Municipal de Ensino de Porto Alegre? 


\section{Artigos Originais \\ Lisandra O. e Silva, Vicente M. Neto}

\section{Considerações metodológicas}

Para realização desta pesquisa corroboramos o entendimento de Sancho Gil (1999, p. 40) de que o "[...] conhecimento há de emergir da reflexão sobre a experiência, da atuação de professores e alunos e não da investigação descontextualizada". Desse modo, refletimos sobre a realização de pesquisas na atualidade enquanto um processo de produção de conhecimento (e de aprendizagens) entre sujeitos (SILVA, 2009).

A análise qualitativa dos fenômenos, como forma de produzir conhecimento, procura descrever, compreender e interpretar os significados, os sentidos, as representações, os discursos que os sujeitos constroem e a que são submetidos no contexto em que se realizam. De acordo com Eisner (1998), os(as) autores(as) e pesquisadores(as) que procuram compreender qualitativamente os fenômenos educativos se preocupam em analisar e explicar a dinâmica das relações sociais. Kincheloe e McLaren (2006), compreendem a Pesquisa Qualitativa a partir da Hermenêutica Crítica e destacam a importância da interpretação nessa forma de fazer pesquisa.

Compreendendo a pesquisa como uma ação coletiva, construída com o local em que está sendo realizada, e com os sujeitos colaboradores e demais grupos do contexto pesquisado, percebemos no estudo de tipo etnográfico e narrativo o caminho para realizar esta investigação. Assim, procuramos ir além dos aspectos descritivos e interpretativos possibilitados pela etnografia (GOETZ; LeCOMPTE, 1984, TRIVIÑOS, 2001, TRIVIÑNOS; MOLINA NETO, 1999, WOODS, 1986), destacando a perspectiva da pesquisa narrativa (CLANDININ; CONNELY, 2011, PÉREZSAMANIEGO et al., 2011), considerando, assim, os aspectos interpretativos dos(as) pesquisadores(as), e, ao mesmo tempo, confrontando-os com as interpretações dos(as) próprios(as) colaboradores(as) da pesquisa - neste caso, docentes e estudantes. 
Deste modo, o que procuramos fazer nesta pesquisa foi, além de analisar, interpretar e compreender a perspectiva dos(as) colaboradores(as) a partir de nossa perspectiva; compreender e apresentar que os(as) colaboradores(as) podem e devem ser analisados(as), interpretados(as) e compreendidos(as) sob a perspectiva deles(as) mesmos(as). A partir disso, realizamos uma pesquisa que circulasse entre a etnografia e a narrativa, utilizando elementos das duas formas de pesquisa para melhor compreender o problema de conhecimento. Assim, utilizamos as descrições e as interpretações (da etnografia) e procuramos compreender a construção da experiência dos sujeitos, a partir de suas perspectivas narradas e vividas (da pesquisa narrativa).

Consideramos que um dos pontos-chave da pesquisa narrativa é dar conta de tematizar narrativamente os textos de campo, transformando-os em textos de pesquisa. Em nossa perspectiva, Clandinin e Connely aproximam a pesquisa narrativa da etnografia, quando expressam o seguinte:

A fim de fazer parte das histórias construídas ao longo da pesquisa, de se tornar parte de uma paisagem, o pesquisador precisa se inserir nesta por um bom tempo, prestar atenção e questionar as situações para compreender os eventos e histórias, as muitas narrativas que se inter-relacionam a cada instante e que apontam, frente a seu olhar ainda inexperiente, caminhos na compreensão de mistérios. [...] Podem ser que digam que a intimidade de um pesquisador narrativo é ser capaz de entrar em consenso com seus participantes. (CLANDININ; CONNELY, 2011, p. 115)

Complementando a análise da pesquisa etnográfica com a pesquisa narrativa, enquanto metodologias de pesquisa, é possível pensar que um modo de pesquisa trata de compreender os significados construídos a partir de um grupo - etnografia - e, o outro modo trata de compreender os significados construídos a partir 


\section{Artigos Orignais}

Lisandra O. e Silva, Vicente M. Neto

dos sujeitos - pesquisa narrativa -. Dessa forma, consideramos o aspecto relacional entre as duas perspectivas, de que o significado do grupo é constituído por significados dos sujeitos.

Assim, diante do exposto, é possível pensar que, nesta pesquisa priorizamos, na etnografia, as narrativas dos sujeitos. De acordo com Bueno (2002), a "mudança de paradigma", que traz/coloca o sujeito para o centro de interesse do processo de pesquisa, "[...] pode ser observada nas demais ciências humanas [...] que estão rompendo com os modelos estabelecidos de pesquisa e ousando construir modos próprios de enfrentar suas questões" (p. 14). As narrativas reorganizam e reconstroem as experiências significativas dos sujeitos, propondo, mediante relatos, a articulação com dimensões mais amplas para o entendimento dos fenômenos sociais. Dessa forma, considera a riqueza de experiências que emergem quando os sujeitos realizam uma reflexão sobre seus saberes (BETTI; MIZUKAMI, 1997).

Ao centrar a pesquisa narrativa no campo da Educação Física, Pérez-Samaniego et al. (2011) descrevem o que entendem por narrativa, suas características e destacam alguns motivos da opção do estudo de narrativas no âmbito dessa área de conhecimento. Do mesmo modo, como foi apresentado até o momento, os autores ressaltam que, nos últimos tempos, a investigação narrativa tem ganhado espaço no campo das Ciências Sociais.

Assim, os(as) pesquisadores(as) são narradores(as) e relatores(as) de histórias sobre as histórias de outras pessoas, e o argumento principal do desenvolvimento e uso da investigação narrativa emergem da consideração de que os seres humanos, individual e socialmente, vivem vidas narradas. Associado a esse entendimento está o de que o ser humano é um ser narrativo, que conta histórias, as quais, em grande parte, têm origem no mundo social e cultural em que vive. Nesse sentido, se o sujeito é construído (como ser humano) através de histórias que vive e narra, seguramente a narrativa necessitaria ser parte central das Ciências Sociais e das áreas que têm o ser humano e suas relações

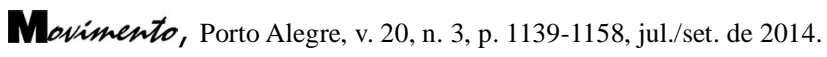


como foco de estudo. A partir dessa perspectiva Pérez-Samaniego et al. (2011) compreendem que a narrativa é condição ontológica para a vida.

Nesta pesquisa, os procedimentos para a obtenção da informação foram desenvolvidos e sistematizados segundo Woods (1986), Triviños (2001), Triviños e Molina Neto (1999), Flick (2004), Goodson (2004), Denzin e Lincoln (2006) e Bolívar, Domingo e Fernández (2001). Dessa forma, servindo-nos de observações participantes, de registros em diário de campo, de entrevistas e de análise de documentos, como opções teóricometodológicas, construímos e aprofundamos conhecimentos sobre os sentidos da escola na perspectiva dos sujeitos que a constituem cotidianamente (sete docentes e 12 estudantes de duas escolas da Rede pesquisada). Para finalizar essa seção, destacamos que para realizar essa pesquisa, os cuidados éticos solicitados foram considerados. Os sujeitos colaboradores foram, em um primeiro momento, convidados a participar do estudo, e, desse modo, informados e esclarecidos sobre o conteúdo e os usos das informações construídas na pesquisa. Ao concordarem em participar, assinaram o "Termo de Consentimento Livre e Esclarecido"".

\section{Categorias de análises}

Apresentamos, neste momento, as cinco categorias interpretativas construídas na pesquisa a partir das narrativas de docentes e estudantes da Rede pesquisada: (1) Escola e as relações com o conhecimento; (2) Escola e Educação Física; (3) Escola e os desafios vividos pelos colaboradores no seu cotidiano na atualidade, (4) Escola, mudanças e projetos; e (5) Pensar o sentido da escola é pensar o sentido da vida, discutidas a seguir.

${ }^{2} \mathrm{O}$ Termo e o Projeto de Pesquisa inicial foram aprovados pelo Comitê de Ética em Pesquisa da Universidade, sob o processo número 19702.

Movimento, Porto Alegre, v. 20, n. 3, p. 1139-1158, jul./set. de 2014. 


\section{Artigos Originais \\ Lisandra O. e Silva, Vicente M. Neto}

\subsection{Escola e as Relações com o Conhecimento}

É importante destacar que tanto docentes quanto estudantes, quando perguntados sobre o(s) sentido(s) da escola na atualidade, ressaltaram que a escola é importante porque lida com conhecimentos, saberes, ensinos, aprendizagens e relacionam o contexto da aula e das disciplinas, como o centro dessas construções.

Foi possível aprender considerações importantes para a compreensão do problema de conhecimento da pesquisa: (1) o entendimento da escola como um dos locais - e não necessariamente o central - de acesso e de construção de conhecimento; (2) as necessidades e desafios para relacionar o conhecimento historicamente construído com a realidade vivida pelos estudantes; e (3) o dilema da fragmentação do conhecimento e com isso, a busca de ações e projetos que incidam em práticas e atitudes interdisciplinares.

Quanto ao primeiro aspecto, é necessário destacar o entendimento de que escola é um dos locais em que estudantes podem aprender e construir conhecimentos, pois, fora dela, têm contato com diversas outras formas de aprendizagem - mídia, celular, internet, redes sociais - e de outros espaços que podem ser mais interessantes e nos quais se sentem identificados. Além disso, o sentido de escola relacionado com o mundo do trabalho (de que na escola se constrói conhecimentos e aprendizagens que podem ajudar a conseguir um trabalho e nas escolhas do futuro) emergiu nas narrativas dos(as) estudantes. Nesse sentido, a construção de conhecimentos (e de aprendizagens) nos contextos de aula e uma suposta escolha (de trabalho) proporcionada pelos componentes curriculares são sentidos que os(as) estudantes conferem à escola, compreendida como um mundo de possibilidades.

No que se refere ao segundo aspecto, é importante destacar que a diversidade de temas que atravessam a vida escolar (educação sexual, educação ambiental, valores, direitos e deveres, entre outros) parece ser uma marca que desafia os(as) docentes em 
sua prática pedagógica e os exige a articular as situações concretas vividas pelos sujeitos em seus contextos, visando à transformação da realidade social vivida pelos(as) estudantes.

Refletindo sobre o terceiro aspecto, as narrativas docentes apresentaram alternativas a partir de projetos compartilhados coletivamente (por exemplo, as formas de trabalho em rede e interdisciplinar), como ações que procuram permitir que o mundo da vida inunde o mundo da escola.

\subsection{Escola e Educação FísICA}

Consideramos a Educação Física uma área multidisciplinar, que tematiza pedagogicamente práticas corporais da cultura corporal do movimento: esportes, ginástica, jogos, lutas, danças, e outras práticas do conjunto que constitui essa cultura (BRACHT, 1996; 2010). Para compreender o que os(as) docentes fazem nas escolas tornou-se necessário conhecer sua história, experiências docentes, processos formativos, o modo como constroem as relações no contexto escolar, dentre outros aspectos que constituem essas práticas.

Se por um lado foi possível perceber que o esporte se configura como conhecimento central entre os temas da cultura corporal de movimento trabalhado nas aulas de Educação Física observadas nesta pesquisa, por outro, os(as) docentes das escolas pesquisadas estão comprometidos em modificar a cultura escolar em relação a essa prática. Nesse sentido, é necessário destacar que alguns(mas) docentes de Educação Física procuram organizar a sua prática pedagógica, relacionando os conhecimentos específicos dessa área com os conteúdos desenvolvidos pelos(as) docentes referência ${ }^{3}$ das turmas do ciclo A, ou seja, procuram, a partir de suas condições de trabalho, realizar um trabalho em conjunto. Do mesmo modo, foi possível perceber que outros(as) docentes estão procurando pensar e discutir sobre a prática pedagógica da Educação Física na escola,

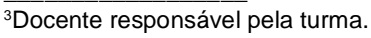

Movimento, Porto Alegre, v. 20, n. 3, p. 1139-1158, jul./set. de 2014. 


\section{Artigos Originais \\ Lisandra O. e Silva, Vicente M. Neto}

ao mesmo tempo em que procuram propor algumas mudanças na estrutura organizacional e pedagógica da área: nas mudanças no trato pedagógico do esporte realizado na escola, focando o desafio de trabalhar com meninos e meninas juntos na aula e na realização das atividades; a ênfase nos elementos de coletividade, colaboração e compreensão de que cada estudante tem seu tempo de aprender o realizar corporal; discussões no início e no final da aula sobre o que realizaram e aprenderam nesta, dentre outros. Do mesmo modo, a inclusão de outros temas da cultura corporal de movimento e outras práticas pedagógicas nas aulas de Educação Física está sendo realizada.

Os sentidos conferidos à Educação Física pelos(as) estudantes e as aprendizagens construídas nessas aulas podem assim ser sintetizados: práticas corporais e esportivas; respeito, apoio e superação; momento de liberdade do corpo; saúde e possibilidade de cuidar do corpo; lazer e a construção desse espaço no interior da escola e na comunidade.

Em síntese e não focando a análise para as perspectivas diferentes apresentadas por docentes e estudantes, e sim, apresentando a diversidade de construção de sentidos, foi possível compreender que Educação Física passa por um processo de mudança, visto que, vem sendo pensada como um componente curricular e de que modo pode estar articulada com o projeto pedagógico educacional de escola. Portanto, é possível pensar que os sentidos conferidos à Educação Física estão interligados aos sentidos conferidos à escola, o que pôde ser observado nas narrativas de alguns docentes quando, ao refletirem sobre o sentido da escola, complementavam: "e a Educação Física vai pelo mesmo caminho".

\subsection{Escola e os Desafios Vividos pelos Colaboradores no seu Cotidiano na Atualidade}

Dentre os conhecimentos construídos nesta categoria destacamos que um dos desafios vividos pelos(as) docentes no

Movimento, Porto Alegre, v. 20, n. 3, p. 1139-1158, jul./set. de 2014. 
cotidiano da escola, na atualidade, refere-se às experiências narradas sobre o choque cultural que enfrentaram e alguns(mas) ainda estão enfrentando ao ingressar na RMEPA, o qual tem menos relação com o(a) docente ser iniciante na profissão e mais em ser iniciante em um contexto novo de trabalho. O choque cultural pôde ser compreendido através de experiências desafiadoras e desconfortáveis vividas pelos(as) docentes ao se confrontarem com as adaptações decorrentes de seu ingresso na Rede: em relação aos(às) estudantes, às diferentes culturas, às formas de acolhimento da Rede e da escola, dentre outras. Ao mesmo tempo, o choque pedagógico, vivido por outros(as) docentes, contribuiu para perceberem algumas contradições ao ingressarem na RMEPA, especialmente, entre o que conheciam do projeto de ciclos de formação e o que encontraram, de fato, nas escolas e as discussões sobre interdisciplinaridade e a fragmentação do conhecimento.

Os principais desafios narrados pelos(as) docentes, com os quais têm que lidar na escola, tratam das situações de vulnerabilidade social que vivem os(as) estudantes e seus núcleos familiares em relação ao contato, ao uso e aos processos de reabilitação relacionados às drogas ilegais; estudantes que vivem casos de violência doméstica; núcleos familiares "desestruturados" e envolvidos com alcoolismo; manifestações de atitudes de violência entre estudantes nas aulas, dentre outras.

Em relação às práticas pedagógicas da Educação Física, os(as) docentes narraram que as negociações, acordos e desacordos são processos diários que realizam nas aulas para que possam realizar sua prática e, por vezes, percebem-se mais críticos(as) e reflexivos(as) e, em outros momentos, mais civilizadores(as), por conta, entre outros motivos, dos conflitos manifestados pelos(as) estudantes, na escola, que interferem na prática pedagógica. Essas situações enfrentadas no cotidiano são consideradas, por alguns(mas) docentes, um dos desafios pedagógicos que as escolas e os(as) docentes de Educação Física vivenciam na atualidade.

Os(as) estudantes narraram que os desafios vividos na escola 


\section{Artigos Orignais}

Lisandra O. e Silva, Vicente M. Neto

estão conectados às construções de relações sociais com os(as) colegas que ocorrem nesse contexto e às formas de intolerância vividas em relação ao outro. Assim, as brigas e as discussões (que acontecem entre estudantes) e o desrespeito (que acontece entre estudantes e entre estes(as) e docentes), tanto nas aulas quanto em outros espaços do contexto escolar (pátio, recreio, dentre outros), foram narrados como situações desafiadoras e desagradáveis experienciadas na escola. Esses acontecimentos chamam a atenção para o enfrentamento do outro e do diferente e desafiam a lidar com a diversidade no contexto escolar.

\subsection{Escola, Mudanças e Projetos}

As análises e discussões propostas nessa categoria consideram as reflexões e as práticas de um projeto realizado em uma das escolas pesquisadas, que objetivaram pensar sobre os sentidos da escola nos dias atuais. Esse projeto, denominado Mix, trata de repensar os fazeres na escola, especialmente em dois aspectos: 1) na quebra da organização das atividades por área de conhecimento; 2) na possibilidade de horizontalizar as relações pedagógicas, ressignificando lugares e saberes. Essa ressignificação de saberes é manifestada tanto na forma como os estudantes convivem no Mix - construindo conhecimento nas trocas - quanto na relação que constroem com esse conhecimento nesse contexto.

É necessário mencionar que a cada trimestre os docentes individualmente ou em duplas organizam, planejam, realizam e avaliam práticas pedagógicas a partir de um tema específico, considerando os interesses dos estudantes. Esses Mix são apresentados para todas as turmas no início de cada trimestre e os estudantes se inscrevem naquele que desejarem realizar ${ }^{4}$. A partir

\footnotetext{
${ }^{4}$ Os Mix oferecidos nos anos de 2011 e 2012 foram os seguintes: Grêmio Estudantil, Mosaico/ Arte/Paisagem, Mitos e Crenças, Sabores da escola, Filoescritura de Kafka, Music and Fun, Memórias, Contando a História da Festa Junina da escola, Naturalizando as Deficiências, Todo Mundo pode Aprender, Cinemix, A Quinta Essência de Mário Quintana, Como Funciona o Brasil?, Do Compasso ao Espaço, LIAUMIX, Inglês, Sexualidade, Preparação para o Trabalho, Encontros Poéticos Musicais na Rio Grande, Customização, Jogos da Vida, Jornal da Escola, Internetês e Pesquisando eu também Aprendo.
}

Movimento, Porto Alegre, v. 20, n. 3, p. 1139-1158, jul./set. de 2014. 
disso, em nossa perspectiva, se constitui a primeira ressignificação de lugar desse projeto: cada grupo do Mix é formado por estudantes dos ciclos $\mathrm{B}$ e $\mathrm{C}$, sendo que, a turma de cada ano ciclo dá lugar à turma do Mix tal ${ }^{5}$.

Assim, é possível pensar que a construção de conhecimentos, a partir de uma disciplina específica, dá lugar à construção de conhecimentos a partir de um tema. Do mesmo modo, consideramos que esse grupo do Mix possibilita aos estudantes transitarem em espaços de aprendizagem diferentes, nos quais convivem com colegas não apenas de ano ciclo diferente, mas, inclusive, com colegas de outro ciclo, dialogando, argumentando, aprendendo sobre os temas de cada Mix e na relação com outro. A ressignificação de saberes é manifestada tanto na forma como os estudantes convivem no Mix, construindo conhecimento nas trocas entre docentes e estudantes, quanto na relação que constroem com o conhecimento tratado nesse contexto.

A quebra de lógicas, estruturas e rotinas, citadas acima, pode ser aproximada com o entendimento de Hernández (2007) quando destaca algumas narrativas naturalizadas sobre a escola configuradas no século XVI e ainda presentes na atualidade, por exemplo: de que a única forma de agrupar os estudantes na escola é por idades; apenas um professor deve trabalhar com cada turma; os livros-texto são a fonte principal do aprendizado; o espaço da sala de aula há de ser fechado para facilitar o controle do grupo; as provas dão conta do que os estudantes têm aprendido; separar por disciplinas é a melhor forma de planejar o que se deve ensinar; os horários fragmentados são a única maneira de organizar o tempo escolar; dentre outras.

É possível pensar que, em relação à análise apresentada, nessa categoria, a atividade do Mix confere sentido à escola na atualidade, propondo algumas mudanças de formas, de espaços, de organizações, de práticas pedagógicas, de propostas de construção

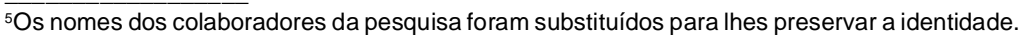

Movimento, Porto Alegre, v. 20, n. 3, p. 1139-1158, jul./set. de 2014. 


\section{Artigos Originais}

Lisandra O. e Silva, Vicente M. Neto

de conhecimentos, dentre outras. As ações do projeto, do mesmo modo, proporcionam aos(às) docentes formas de realizar um trabalho coletivo a partir da interlocução com outros(as) docentes e com os(as) estudantes. É possível pensar que o projeto possibilita quebras de algumas institucionalizações de tempos, de espaços e de formas de conhecer e de construir conhecimentos na escola.

\subsection{Pensar o Sentido da Escola é Pensar o Sentido da Vida}

No diálogo com os(as) colaboradores(as), a escola foi referida como um espaço de construção de laço social que, de algum modo, sugere que os sujeitos que nela vivem cotidianamente constroem significações que ultrapassam o vivido nos tempos/espaços da instituição escolar. Por isso, pensar o sentido da escola convida que se pense $\mathrm{o}(\mathrm{s})$ sentido(s) da vida no entrecruzamento de experiências que se realizam diariamente nesse contexto.

Portanto, as reflexões construídas sobre a vida escolar, a vida docente e a vida estudantil, procuraram compreender o modo com que os sujeitos constroem, no cotidiano, as relações com os outros e com o mundo: nos grupos em que trabalham e estudam; nas crenças e entendimentos que orientam a prática pedagógica dos(as) professores, dentre outros. Ao refletirem sobre o sentido da escola, os(as) estudantes o fazem a partir do que vivem no cotidiano do contexto escolar e na interação com o mundo. Para eles(as), a escola é compreendida como um local que possibilita dar conta de seus projetos de vida, do que desejam estudar e aprender, da escolha de uma profissão, de construção de relações sociais, ou seja, a escola como possibilidade.

É possível pensar que, por exemplo, quando o docente Paulo narra que "ali naquele espaço que a gente tá vivendo, dá o nosso sangue, dá o nosso carinho, dá a nossa esperança pras pessoas que tão ali envolvidas", e quando a estudante Gerusa destaca que "ele [colégio] é importante pra mim poder abrir novos caminhos, pra mim ir mais adiante, tipo, realizar o meu sonho, eles tão me ajudando a ser", os sentidos conferidos à escola se cruzam nesse

Movimento, Porto Alegre, v. 20, n. 3, p. 1139-1158, jul./set. de 2014. 
desejo de que a escola possa oferecer algo que vá mais além da própria experiência escolar; sentidos apoiados, também, pelo desejo em dar conta de seus projetos de vida.

Não é novidade que a escola não está descolada da realidade e é permeável aos contextos sociais em que se insere. Nas narrativas parece ser esse contexto que provoca a escola e que merece maior protagonismo nas relações com os conhecimentos nela construídos, pois argumenta o docente Paulo, os conhecimentos devem partir dos problemas e das situações concretas vividas pelos sujeitos em seus contextos.

Assim, nessa categoria procuramos compreender a relação da escola com a vida, pois, ao se procurar entender, estudar, trabalhar em um local, onde as pessoas constituem e passam parte de suas vidas juntas, essa compreensão se refere à experiência de vida, de viver e da formação humana.

\section{Considerações finaIs}

Os sentidos conferidos à escola na perspectiva dos(as) estudantes podem ser considerados em três esferas: a escola como espaço para aprender cada vez mais; a escola que ajuda no futuro; a escola que possibilita escolhas e ajuda em seus projetos de vida. As aprendizagens construídas nas aulas de Educação Física e os sentidos conferidos pelos(as) estudantes a esse componente curricular podem ser assim sintetizados: (1) práticas corporais e esportivas: atividades de alongamento e as relacionadas aos esportes; (2) respeito, apoio e superação; (3) momento de liberdade do corpo; (4) saúde e possibilidade de cuidar do corpo, de si e de poder ter uma vida saudável, (5) lazer e a construção desse espaço no interior da escola e na comunidade. Do mesmo modo, os(as) estudantes destacam alguns elementos que contribuem para que aprendizagens significativas possam ser construídas tanto nas aulas de Educação Física quanto nos outros componentes curriculares: boas explicações por parte dos docentes; preocupação dos docentes em ensinar e não em "passar a matéria"; aulas dinâmicas (não 


\section{Artigos Originais}

Lisandra O. e Silva, Vicente M. Neto

somente copiar do quadro e explicações breves); construção de vínculo entre docentes e estudantes; dentre outros.

Para os(as) docentes, os sentidos conferidos à escola e à Educação Física são múltiplos e estão pautados nas experiências e reflexões realizadas a partir de sua prática pedagógica e do que é possível realizarem nessas aulas; nos processos formativos; em suas histórias de vida; dentre outros elementos constitutivos da docência. A escola entendida como uma instituição educadora e assistencialista; um dos locais de construção de conhecimento; que possibilite a transformação da sociedade e a formação de estudantes críticos(as) e reflexivos(as); que possibilite trabalhar de forma coletiva e interdisciplinar; que equilibre o conhecimento historicamente acumulado pela humanidade com a realidade vivida pelos(as) estudantes, foram algumas das significações conferidas pelos(as) docentes. A partir disso, em relação à Educação Física escolar, foi possível compreender que esta vem constituindo-se componente curricular na escola, sendo percebida como um espaço capaz de insuflar discussões que sugerem uma busca de sentido, outrora preenchido pela atividade física e a prática hegemônica do esporte.

As narrativas se distanciam no próprio sentido que os(as) docentes conferem à escola, de que modo se percebem nesse contexto e o que conseguem realizar em suas práticas pedagógicas. Em contrapartida, as narrativas se aproximam quando destacam a importância do fazer coletivo e das aprendizagens realizadas com os pares nesse contexto. Assim, os(as) docentes parecem compartilhar os sentidos conferidos à escola e à educação ao narrarem que a docência não se constrói isoladamente e que tal instituição os desafia na necessidade de pensar/organizar/concretizar suas ações de modo mais articulado uns com os outros. Nesse sentido, algumas narrativas docentes apresentaram alternativas a partir de projetos compartilhados coletivamente.

Para finalizar, chamo a atenção para a relação entre educação e escola; que o que acontece e o que se faz no contexto escolar 
tem relação com a educação dos sujeitos, ou, como observa Morin (2007), com a construção de meios e de fazeres que permitam e contribuam para a formação e o desenvolvimento de um ser humano. Permitir, contribuir, colaborar, propor a formação e o desenvolvimento do sujeito é lidar com a vida humana, ou seja, com vidas que se entrecruzam em um momento histórico e em um contexto específico. Assim, educação, formação e desenvolvimento podem ser pensados a partir da construção de relações entre sujeitos que educam e são educados, transformam e são transformados, aprendem e ensinam em uma relação direta consigo mesmos, com os outros e com o mundo.

Foi possível entender que o desafio humano de educar e participar do processo de formação e desenvolvimento de sujeitos - mediado pela construção de relações sociais - parece estar na pauta de uma prática social continuamente incompleta, inconclusa, dada a dimensão do inacabamento humano e as contingências da vida. 
The meanings of the school and the Physical Education for the students and teachers of a rede publica municipal

Abstract: Considering that recent social changes have been motivating effects in the school life, this research had as the main goal understand the meaning of school and Physical Education from the meanings given by teachers and students of a Rede Publica Municipal. Having observations of participants, field diary, interviews and analyses of documents like theoretical methodologic options, we built up five interpretative categories that are the main focus of discussion of this article: School and its links with knowledge; School and Physical Education; School and the challenges lived by its workers in their present everyday lives; School, changes and projects; Thinking the meaning of school is thinking the meaning of life.

Key-words: School. Physical Education. Teachers. Students.

Los sentidos de la escuela y de la Educación Física para los estudiantes y profesores de la red de escuelas públicas del ayuntamiento de Porto Alegre

Resumen: Considerando que recientes cambios históricos $y$ sociales han generado efectos en la vida escolar, esta investigación tuvo como objetivo comprender los significados de la escuela y de la educación física desde el significado conferido por los profesores y estudiantes de una red de escuelas públicas de una ciudad del sur de Brasil. Hemos utilizado la observación participante, el diario de campo, las entrevistas y el análisis de documentos como opciones teórico-metodológicas. Construimos cinco categorías interpretativas, que son el foco de la discusión de este artículo: Escuela y las relaciones con el conocimiento; Escuela y Educación Física; Escuela y los retos que experimentan los profesores y estudiantes en su cotidiano en los tiempos actuales; Escuela, cambios y proyectos; Pensar el sentido de la escuela es pensar el sentido de la vida.

Palavras-clave: Escola. Educação Física. Docentes. Estudantes. 
Os sentidos da escola e da Educação Física para ...

\section{REFERÊNCIAS}

ARROYO, Miguel G. Ofício de mestre: imagens e auto imagens. 6. ed. Petrópolis: Cortez, 2000.

BETTI, Irene C. Rangel; MIZUKAMI, Maria da Graça Nicoletti. História de vida: trajetória de uma professora de educação física. Motriz, Rio Claro, v. 3, n. 2, p. 108-115, dez. 1997.

BOLÍVAR, Antonio; DOMINGO, Jesús; FERNÁNDEZ, Manuel. La investigación biográfico-narrativa en educación: enfoque y metodología. Madrid: Editorial La Muralla, 2001.

BRACHT, Valter. Educação Física no $1^{\circ}$ grau: conhecimento e especificidade. Revista Paulista de Educação Física, São Paulo, supl. 2, p. 23-28, 1996.

BRACHT, Valter. A educação física no ensino fundamental. In: SEMINÁRIO NACIONAL CURRÍCULO EM MOVIMENTO: PERSPECTIVAS ATUAIS, 1, 2010. Anais. Belo Horizonte. Disponível em: <http://portal.mec.gov.br/index. php?option=comcontent\&view=article\&id= 16110\&ltemid 936>. Acesso em: $14 \mathrm{fev}$. 2012.

BUENO, Belmira Oliveira. O método autobiográfico e os estudos com histórias de vida de professores: a questão da subjetividade. Educação e Pesquisa, São Paulo, v. 28, n. 1, p. 11-30, jan/jun, 2002.

CLANDININ, D. Jean; CONNELLY, F. Michael. Pesquisa narrativa: experiência e história em pesquisa qualitativa. Uberlândia: EDUFU, 2011.

DENZIN, Norman K.; LINCOLN, Yvonna S. O planejamento da pesquisa qualitativa: teoria e abordagens. 2. ed. Porto Alegre: Artmed, 2006.

EISNER, Elliot W. El ojo ilustrado: indagación cualitativa y mejora de la práctica educativa. Barcelona: Paidós, 1998.

FLICK, Uwe. Uma introdução à pesquisa qualitativa. Porto Alegre: Bookman, 2004.

GOETZ, J. P.; LeCOMPTE, M. D. Etnografía y diseño cualitativo en investigación educativa. Madrid: Morata, 1984.

GOODSON, Ivor F. Historias de vida del profesorado. Barcelona: OctaedroEUB, 2004.

HERNÁNDEZ, Fernando. O problema está na narrativa e na resistência em mudála. In: HERNÁNDEZ, Fernando. Catadores de cultura visual: transformando fragmentos em nova narrativa educacional. Porto Alegre: Mediação, 2007. p. 11-19.

KINCHELOE, Joe L.; MCLAREN, Peter. Repensando a teoria crítica e a pesquisa qualitativa. In: DENZIN, Norman K.; LINCOLN, Yvonna S. O planejamento da pesquisa qualitativa: teorias e abordagens. Porto Alegre: Artmed, 2006. p. 281-

Movimento, Porto Alegre, v. 20, n. 3, p. 1139-1158, jul./set. de 2014. 


\section{Artigos Originais}

Lisandra O. e Silva, Vicente M. Neto

313.

MOREIRA, Antonio Flavio Barbosa; SILVA, Tomaz Tadeu da. Sociologia e teoria crítica do currículo: uma introdução. In: MOREIRA, Antonio Flavio Barbosa; SILVA, Tomaz Tadeu da. (Org.). Currículo, cultura e sociedade. 2. ed. São Paulo: Cortez, 1995. p. -37.

MORIN, Edgar. Educar na era planetária: o pensamento complexo como método de aprendizagem pelo erro e incerteza humana. 2. ed. São Paulo: Cortez, 2007.

PÉREZ GÓMEZ, Angel I.. La cultura escolar e la sociedad neoliberal. Madrid: Morata, 1998.

PÉREZ-SAMANIEGO, Víctor M. et al. La investigación narrativa en la educación física y el deporte: que és y para qué sirve. Movimento, Porto Alegre, v. 17, n. 1, p. 11-38, jan./mar. 2011.

SANCHO GIL, Juana Maria. Inovação e investigação educativa: aproximação a uma relação incerta. In:TRIVIÑOS, Augusto Nibaldo Silva; MOLINA NETO, Vicente (Org.). A pesquisa qualitativa na educação física: alternativas metodológicas. Porto Alegre: UFRGS/Sulina, 1999. p. 29-43.

SILVA, Lisandra Oliveira e. Produção de conhecimento (e de aprendizagem) entre sujeitos: o desafio da pesquisa. In: MOLINA NETO, Vicente et al. Quem aprende? Pesquisa e formação em educação física escolar. ljuí: Unijuí, 2009. p. 143-155.

TRIVIÑOS, Augusto Nibaldo Silva. Bases teórico-metodológicas da pesquisa qualitativa em ciências sociais: idéias gerais para a elaboração de um projeto de pesquisa. Porto Alegre: Faculdades Integradas Ritter dos Reis, 2001.

TRIVIÑOS, Augusto Nibaldo Silva; MOLINA NETO, Vicente (Org.). A pesquisa qualitativa na educação física: alternativas metodológicas. Porto Alegre: UFRGS/ Sulina, 1999.

WOODS, Peter. La escuela por dentro: la etnografía en la investigación educativa. Barcelona: Paidós, 1986.

Endereço para correspondência:

Rua dos Andradas, n. 531, apto 709

Bairro Centro Histórico

90020-001 - Porto Alegre - RS

Recebido em: 22.06.2013

Aprovado em: 04.06.2014

Movimento, Porto Alegre, v. 20, n. 3, p. 1139-1158, jul./set. de 2014. 